are special reasons why the professional community has a special role to play in ridding the nuclear wrangle - it is not an honest debate - of mumbo jumbo. Here and elsewhere, however, the responsibility for getting things done lies also with governments. If higher (or even higher) energy taxes are thought necessary, it is for them to persuade their voters that the benefits will be worthwhile - the chance to remain citizens of progressive yet dynamic communities. If strip mines, or ordinary coal mines, or nuclear power plants, are necessary, governments have a duty to make sure that their people know what are the stakes - the avoidance of economic debacie, to put it at its mildest; at the other end of the spectrum, the avoidance of the much more serious trouble there would be bound to be if, say, Saudi Arabia were unable to produce 11 million barrels of oil each single day.

Telling it like it is is unfortunately unfashionable. Signing communiques is easier. So too is making promises for the long term that become confused in voters' minds with solutions to immediate problems. President Carter's promise two years ago that 20 per cent of American energy production would come from the sun by the end of the century is of this kind. For the industrialized West, the question is not that of what the energy mix will be in the year 2000 but how to get from here to there. Implicitly, that is what the heads of government at Venice said. They had better now tell their people even if, as a result, they suffer the traditional fate of the bearers of bad tidings. They might make their message more palatable by seeking more imaginative ways out of their present fix - by counterbalancing the rigged OPEC market in oil with their own free market (Nature, 12 May). This week, for what it is worth, the spot price at Rotterdam has fallen below that charged by some OPEC countries, which can only suggest that the price would fall even more quickly if the market were assured of a regular share of the West's own oil production.

Happily, however, Venice was not entirely a recitation of familiar platitudes. Habitually, the industrialized West has collectively been shy of saying much about it obligation to the developing countries of the world for fear of giving too many hostages to fortune. At Venice, they broke cautiously with precedent and even went as far as to "welcome" the report of the Brandt Commission, promising to "study" its recommendations. They also undertook not to organize their policies on international trade in ways that would be harmful to the non-oil developing countries. That is as it should be, although it is doubtful whether the Venice signatories appreciate the magnitude of their undertaking; it implies nothing less than recreation of their industrial base at a time of perhaps indefinite recession. Such magnanimity will not come easily to the unemployed shoeworkers of New England or the unemployed workers of the British steel and motor car industries. Nor is there much hope that the industrialized West can share this burden with other states.

\title{
Why bother with school examinations?
}

LIKE Stratford-upon-Avon, the Changing of the Guard and the game of cricket, the British examination system is one of those characteristically British phenomena which the rest of the world knows it will never understand. Increasingly, the British are in the same plight. Now that the examinations season is at an end, when only the most diligent of those who have survived their recent trauma have begun preparing for the next, and when many of those responsible for assessing the gigantic paper output of the examination system have withdrawn temporarily from the real world, it may be safe to raise the question whether the system as a whole is worth preserving. The answer is not simple. Plainly the system cannot be entirely swept away but it is equally unthinkable that it should be preserved in its present form.

The rules of the game are worth a little effort to understand, if only for the light that understanding may throw on what must surely be one of the most pathetic of human frailties - the belief that ordinary men and women in some stratum of the academic profession can reduce any other person's quality to a number of some kind, usually between zero and 100. One of the curiosities of the recent proliferation of examinations in Britain is that in the 1950 s the country was riven into the camps of those who passionately held that it is possible by means of an examination to tell at the age of eleven whether a child should have an academic or grammar school education, and the camp of those who considered the eleven-plus examination to be unjust. In the end, the abolitionists more or less won the day, comprehensive schools were invented and for a time preoccupation with school examinations seemed to have been stilled.

Alas, the wish to examine and to be examined has since reasserted itself with a vengeance. Increasing numbers of no doubt fond parents now subject their sons and daughters, often at the age of seven or eight, to the competitive examinations put up as hurdles by the fee-paying schools, knowing that their of fspring will thereafter be graded once a year either by means of a number or, more elegantly, by a letter from the Greek alphabet, with pluses or minuses appended. For most British children, the first external yardstick comes at about 16 , the age of $O$ (which stands for "Ordinary") level, or alternatively of "CSE" (which stands for Certificate of Secondary Education). The word that echoes around the corridors of secondary education is that you cannot get a job unless you do reasonably well in one or other.

In ancient days (but even now in Scotland) there used to be an examination called "School Certificate" devised at least in part to meet the entrance requirements of universities. Since entry to universities was in question, universities came to dominate the committees which administered these examinations. Knowing that not every university could run its own examinations board, the universities grouped themselves into consortia, of which there at present nine, and which now administer the O-level examinations and the A (for "Advanced") equivalents, literally used by most universities as a way of telling which students should be given a chance to study something serious.

The problems of the sixteen-plus examination are unfortunately minor compared with those which crop up two years later. The rules of the game, in Britain, are that those wishing to find themselves a place in a university are required not merely to jump the hurdle of the O-level examinations but of A-level as well. They are, for practical purposes, required to elect two years in advance for what they will take an interest in at university, and then to prove (with the help of the school-teachers who happen to be around) that they can perform. Many youngsters rebel at choosing, but eventually are forced to toe the line. Others, no doubt, give up, or worse still find they have chosen wrongly. In all secondary schools, teaching A-level students is regarded as the pinacle of academic life (and in many schools it is quite remarkable how successfully the image of specialist can be created at sixteen or seventeen).

If the charge against this part of the British educational system were merely that it is farcical, it might be allowed to continue. The truth is that it is actively harmful. It ensures that young people are too narrowly prepared for the academic life, and frequently have been forced at an early age to choose the wrong disciplines to follow. In justice, and in the national interest of the British, it would be better if A-level were to be abolished. Since, however, that will not happen overnight, it would serve the same purpose if A-level were to be subverted. The way in which this might be done is easy to identify. If only universities were once again to take responsibility for their student entry, and were to select say ten per cent of intending students by some quite different method - a scholastic aptitude test, an interview or some other indicator of performance - the result would be that lots of bright young people would be found to prefer that route. If selection for the people not taking A-level were a year earlier than for the rest, but if university courses were a year longer for the early ten per cent, there would at least be a chance to tell which way was the best. Is it not time that this was tried? 